\title{
LOAD TRANSFER-CRACK WIDTH RELATION OF NON-DOWELLED JOINTED PLAIN CONCRETE SHORT SLABS
}

\author{
Mauricio PRADENA ${ }^{1,2^{*}}$, Lambert HOUBEN ${ }^{2}$ \\ ${ }^{1}$ Dept of Civil Engineering, University of Concepción, Edmundo Larenas 219, \\ Concepción, Casilla 160-C Correo 3, Chile \\ ${ }^{2}$ Delft University of Technology, Section Pavement Engineering, Stevinweg 1, Delft 2628 CN, the Netherlands
}

Received 09 June 2017; accepted 29 December 2017

\begin{abstract}
Non-dowelled short slabs are a cost-effective innovation of jointed plain concrete pavements. The development of this innovation has been concentrated in their structural performance. Still there is a lack of specific studies of the relation load transfer - crack width, being the crack width at joint the direct cause of the aggregate interlock. Considering that their provision of load transfer relies on aggregate interlock, the objective of the present article is to develop the relationship between the load transfer by aggregate interlock and its direct cause (the crack width) specifically for innovative nondowelled short concrete slabs pavements. For that, the analysis includes a validated nonlinear aggregate interlock model incorporated in a 3D Finite Element program, laboratory results, and field measurements performed as part of the present investigation. The results show that due to the small crack widths, the short slabs are able to provide adequate load transfer (not less than 70\%) even without dowels bars. Indeed, in this case, the load transfer relies on aggregate interlock and the results of the Faultimeter (residual value more than 0 ) have confirmed this interlocking for crack widths at joints not more than $1.2 \mathrm{~mm}$, which are typical values in short slabs when the joints are activated. For that, the Early Entry saw cutting method needs to be modified or applied as a complementary method to perform the joints. Although in short concrete slabs pavements the provision of load transfer is already guaranteed by the small crack widths at joints, the application of high-quality coarse aggregates provides even higher load transfer.
\end{abstract}

Keywords: aggregate interlock, concrete pavements, crack width, joints, load transfer, short slabs.

\section{Introduction}

Short concrete slabs are an innovation of traditional Jointed Plain Concrete Pavements (JPCPs). The reduction of slab length also allows less concrete thickness because of the different traffic load configuration and the curling reduction (Covarrubias, 2011; Roesler, Cervantes, \& Amirkhanian, 2012). Even more, the construction costs are reduced up to $25 \%$ due to the use of joints without seals and without dowels bars (Covarrubias, 2011).

Certain aspects of the technology of short concrete slabs have been patented (Covarrubias, 2011, 2012) and the attention has been focused especially to the structural behaviour of this innovation (Covarrubias, 2011, 2012; Roesler et al., 2012; Salsilli, Wahr, Delgadillo, Huerta, \& Sepúlveda, 2013, 2015). For instance, using dimensional analysis (Ioannides, 1984), Salsilli et al. (2015) developed a practical Mechanistic-Empirical (M-E) design method for short slabs with the objective to be available for prac- titioners. In this method, Salsilli et al. (2015) extended the adjustment factor for load transfer of the Westergaard equation for slab edge stress originally developed for traditional JPCPs (Ioannides, Korovesis, 1990). However, Salsilli et al. (2015) recognize the necessity to make specific studies of Load Transfer Efficiency (LTE) in the non-dowelled short slabs. Actually, although the development of short slabs JPCPs has been concentrated to their structural analysis, there is a lack of specific studies of the relation among the LTE by aggregate interlock with its direct cause (the crack width). Considering that their provision of load transfer relies on aggregate interlock, which is the most influential load transfer mechanism in non-dowelled JPCPs (Buch, Frabizzio, \& Hiller, 2000; Hanekom, Horak, \& Visser, 2003; Jensen \& Hansen, 2001), the characterization of the LTE-crack width relation is fundamental. Therefore, the objective of the present article is to develop the rela-

*Corresponding author. E-mail: mpradena@udec.cl

This is an Open Access article distributed under the terms of the Creative Commons Attribution License (http://creativecommons.org/licenses/by/4.0/), which permits unrestricted use, distribution, and reproduction in any medium, provided the original author and source are credited. 
tionship between the LTE by aggregate interlock and its direct cause (the crack width) specifically for innovative non-dowelled short slabs JPCPs.

\section{Research approach and methodology}

Figure 1 shows the research approach and the variables affecting the early-age concrete behaviour that finally determines the crack width to be directly related with the load transfer (which is the focus of the present work). Sometimes these variables (part of them) are also used to create relationships with the load transfer of the in-service JPCP. However, it is important to highlight that they relate the LTE by aggregate interlock with indirect causes instead of the direct cause of it, as it is shown in Figure 1.

To determine the crack width (at joints) of JPCPs, Houben (2010) and Pradena and Houben (2015, 2017) have developed system approach where the cracking pattern is developed in time and space according to the specific conditions of the JPCP under analysis. In effect, certainly the development in time of the material properties affects the cracking process, but also this process is affected by the geometry of the pavement (thickness, slab length), the time of construction of the JPCP and the saw cutting method applied (conventional method or shallow saw cutting), among others. Hence, this approach considers all the interactions in the JPCP system for the prediction of a crack width. The output of such a process is the input to incorporate the aggregate interlock in the M-E structural pavement design. This is possible by establishing a relationship between the load transfer efficiency and the crack width resulting of the early-age behaviour of the JPCP (Figure 1). Pradena and Houben (2016) have validated the model for short slabs JPCPs where $50 \%$ slab length reduction produces $50 \%$ narrower cracks width (at joints) on the traditional JPCP.

However, according to its objective, the present article is focussed on the LTE-crack width relation for innovative non-dowelled short slabs JPCPs. The creation of this relationship relies on the following three methods (Figure 1):

- The nonlinear aggregate interlock model of Walraven incorporated in the 3D Finite Element (FE) program EverFE (validated);
- laboratory results (previous investigations);

- field measurements (present investigation).

The field measurements of the present investigation are performed in a JPCP test section with short slabs built in the facilities of the National Highway Laboratory (NHL) of Chile. In addition, complementary measurements are performed with the Faultimeter of the Belgian Road Research Centre (BRRC).

\section{Results and analysis}

\subsection{Analysis of previous investigations: validated model and laboratory tests}

In the development of the program Hiperpav, Ruiz, Rasmussen, Chang, Dick, and Nelson (2005) state that in non-dowelled JPCPs the aggregate only provides load transfer for crack width not more than $0.5 \mathrm{~mm}$. This limit value appears too conservative when it is compared to other investigations.

The 3D FE program EverFE relies on the two-phase aggregate interlock model developed by Walraven (1994) to generate nonlinear aggregate interlock constitutive relations (Davids \& Mahoney, 1999). Davids and Mahoney (1999) validated this modelling using the experimental data of Colley and Humphrey (1967), which is the classic study of LTE-crack width relationships. Colley and Humphrey (1967) used American aggregates in the laboratory tests. Similar is the case of Jensen and Hansen (2001), where the LTE-crack width relationship was also studied, but especially focused on the influence of large-sized coarse aggregates (using aggregates of United States).

Later, Hanekom, Horak, and Visser (2003) compared the LTE-crack width relationships given by Jensen and Hansen (2001) and EverFE (Davids \& Mahoney, 1999) with the ones obtained in laboratory tests with typical South African aggregates. From this comparison, they found significant differences in the load transfer by aggregate interlock provided by the American aggregates and the South African ones. Figure 2 presents, for the softest aggregate, applied in pavements in South Africa, the results of LTE-crack width obtained in laboratory tests and modelling with the 3D FE program EverFE. In effect,

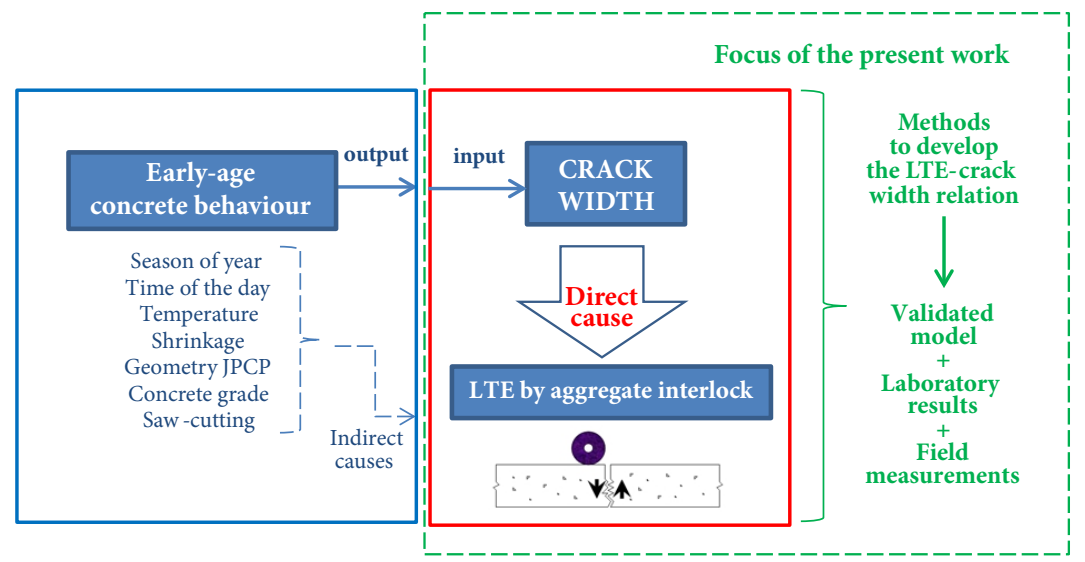

Figure 1. Research approach, focus on the present work and methods to develop the LTE-crack width relation 
the South African study was made with the extremes of aggregate quality of the spectrum of concrete construction aggregates crushed in South Africa. In terms of the Elastic Modulus of the aggregates, the values obtained were $42 \mathrm{GPa}$ (for the hardest aggregates) and $29 \mathrm{GPa}$ (for the softest aggregates). Figure 2 shows the results for the two aggregate sizes studied in South Africa $(19.0 \mathrm{~mm}$ and $37.5 \mathrm{~mm}$ ) under static and dynamic conditions. Even with the softest South African aggregates, the LTE results are always more than $90 \%$ before a crack width $2.3 \mathrm{~mm}$.

Figure 2 also shows the differences obtained in the South African study with the EverFE modelling (using the South African data). EverFE gives smaller LTE values than the ones obtained in the laboratory in South Africa, but higher LTE values than the ones of the validation of the aggregate interlock model with the aggregates of United States of maximum size $38 \mathrm{~mm}$ (Davids \& Mahoney, 1999). In the study of Jensen and Hansen (2001) the LTE 70\% is reached for crack width as small as $0.8 \mathrm{~mm}$ for both aggregates studied (maximum size $25 \mathrm{~mm}$ ) with Elastic Modulus of the aggregates $22 \mathrm{GPa}$ and $24 \mathrm{GPa}$ respectively. The only exception was the very large sized 50 $\mathrm{mm}$ of the stronger aggregate. Actually, the focus of the study of Jensen and Hansen (2001) was the contribution of the large size coarse aggregate in the load transfer efficiency.

As expected, Hanekom et al. (2003) found higher values of load transfer efficiency for the hardest aggregates of the spectrum of concrete construction aggregates crushed in South Africa. However, in the present study, it is highlighted the fact that even the softest aggregate gives already the high LTE values of Figure 2 for static and dynamic loading (where dynamic loading yields the higher values). Finally, as it is also expected, the larger coarse aggregate $(37.5 \mathrm{~mm})$ provides higher load transfer than the aggregate of $19 \mathrm{~mm}$.

Jensen and Hansen (2001) and Hanekom et al. (2003) agree that the base starts to play a role in the LTE when the crack width is not less than $2.5 \mathrm{~mm}$. Indeed, despite the differences in aggregates, the conclusion of these different investigations regarding the contribution of the base on the load transfer efficiency is the same, i.e. the base be-

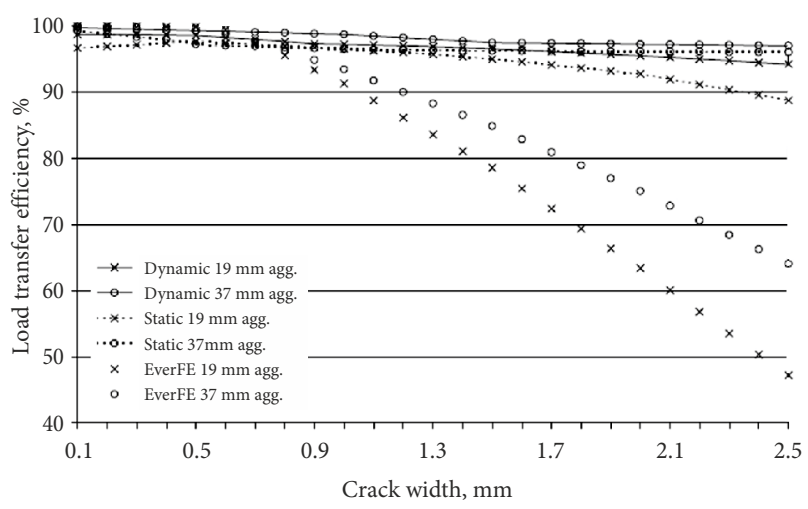

Figure 2. LTE-crack width relations in South African study (Hanekom, Horak, \& Visser, 2001) gins to influence the LTE only since crack widths $2.5 \mathrm{~mm}$. According to Davids and Mahoney (1999) and Pradena and Houben (2015) the crack width in traditional slabs JPCPs is, in general, not more than $2.5 \mathrm{~mm}$. In the case of short slabs the crack width is even narrower, generally not more than $1.2 \mathrm{~mm}$ (Pradena \& Houben, 2016). Hence, for non-dowelled JPCPs, and in particular for short slabs JPCPs, the analysis is focussed in the most influential load transfer mechanism in non-dowelled JPCPs, which is the aggregate interlock (Buch et al., 2000; Hanekom et al., 2003; Jensen \& Hansen, 2001)

\subsection{Field measurements Load Transfer Efficiency and crack width in short concrete slabs}

Salsilli et al. (2015) recognize the necessity to perform specific studies of load transfer in short slabs JPCPs. Although Roesler et al. (2012) performed measurements of LTE in short slabs JPCPs, they did not study the LTEcrack width relationship. Therefore, the field measurements of the present sub-section are concentrated on developing the LTE-crack width relation of this innovation. In this way, field measurements are performed in a short slabs JPCP test section built in the facilities of the NHL of Chile, located in Santiago city (latitude $33^{\circ} 30^{\prime} \mathrm{S}$ ) at the Metropolitan Region of Chile. The characteristics of the test section are as follows: slab length $1.8 \mathrm{~m}$, slab thickness $140 \mathrm{~mm}$, aggregates of $38 \mathrm{~mm}$ (maximum size), no dowel bars, granular base CBR $40 \%$ and concrete flexural tensile strength $5 \mathrm{MPa}$. The deflection LTE was measured with the Falling Weight Deflectometer (FWD) (Figure 3a) and the crack width obtained with fissurometer and microscope (Figure 3b). The FWD loads a slab and measures the deflection of the loaded and the unloaded slabs, which are the inputs to calculate the load transfer efficiency.

With the support of the NHL, measurements of the LTE-crack width relation were performed in the months of March and June. The measurements of March were made on eight joints in the Chilean summer, with $22{ }^{\circ} \mathrm{C}$ as the average temperature of the pavement surface. As the cracking pattern developed, the measurements of June were performed on nine joints at the end of the Chilean autumn with an average temperature of the pavement surface of $12{ }^{\circ} \mathrm{C}$. As a minimum, the load transfer efficiency was measured two times per joint to obtain its average for the crack width at the time of the measurement. It is important to reiterate that the objective of the field measurements was to obtain a spectrum of different crack widths values to develop the direct relation with the load transfer efficiency (Figure 4). Most of the smaller crack widths values of Figure 4 (Zone I) were obtained in March (higher temperature). Moreover, the larger crack width values (Zone II) were obtained at the lower pavement temperature (June). The unusual large crack widths values (for short slabs JPCPs) are explained by the presence of $60 \%$ of uncracked joints due to the shallow Early Entry saw cutting applied. In effect, Early Entry saw cutting consists of a shallow cut (up to $30 \mathrm{~mm}$ depth) that allows a faster 
a) Measurements of LTE with FWD

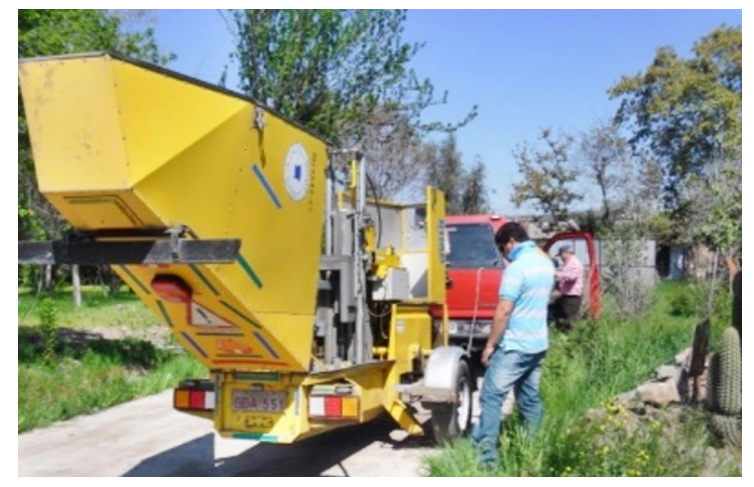

b) Measuements of crack width with microscope

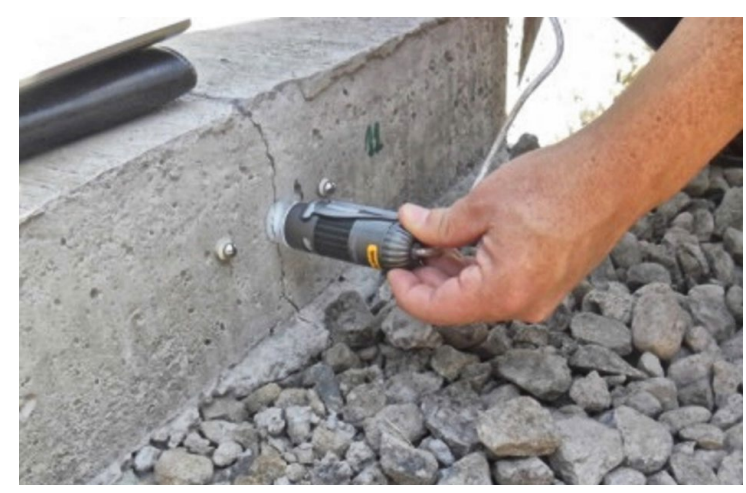

Figure 3. Measurements of LTE and crack width in test section of short concrete slabs

construction of JPCPs because the joints are cut as soon as the slabs support the weight of the operator. Actually, from these results and the ones of Pradena and Houben (2014), it is recommended to apply the Early Entry saw cutting method with modifications or as a complementary method to perform the joints of short slabs JPCPs (more details in Pradena \& Houben, 2014).

Figure 4 is divided into 2 zones, as follows:

- Zone I: until the crack width of $0.7 \mathrm{~mm}$, the effects of the crack width on the LTE are clearly observed.

- Zone II: beyond the crack width of $0.7 \mathrm{~mm}$, an asymptotic behaviour of the LTE, around $80 \%$ is observed.

In Zone I, the LTE values decrease with the increase of the crack widths, from $95 \%$ for crack width $0.1 \mathrm{~mm}$ to $80 \%$ for crack with $0.7 \mathrm{~mm}$ (Figure 4 ). When the crack width continues increasing the expected behaviour is the decrease of LTE. In fact, Figure 5b shows the extrapolation of the function LTE-crack width obtained for Zone I (Figure 5a). However, in Zone II the load transfer efficiency presents an asymptotic behaviour around 80\% (Figure $5 b)$. This behaviour is also observed in the South African study especially for the aggregate of $37.5 \mathrm{~mm}$ (Figure 2). In the case of the hardest South African aggregate, the asymptotic behaviour is even clearer for both sizes of the aggregate, i.e. $19 \mathrm{~mm}$ (Hanekom et al., 2003) and $37.5 \mathrm{~mm}$ (Brink, Horak, Perrie, Strauss, \& Visser, 2004). Therefore, the high quality of the aggregates has a fundamental role in the limitation of further LTE reductions as the crack width increases (for the spectrum of crack width values analysed in the present section). In a similar way, the asymptotic behaviour shown in Figure $5 b$ is explained by the high quality of the Chilean aggregates (Achurra, 2009; Ministry of Housing and Urban Development of Chile 2005: Standards and Technical Specifications for Pavements) of $38.0 \mathrm{~mm}$ applied in the test section. Actually, Achurra (2009) studied the quality of the aggregates of different regions of Chile focussed on the polishing of aggregates. Although Achurra (2009) did not determine the elastic modulus of the aggregates, their mechanical abrasion was

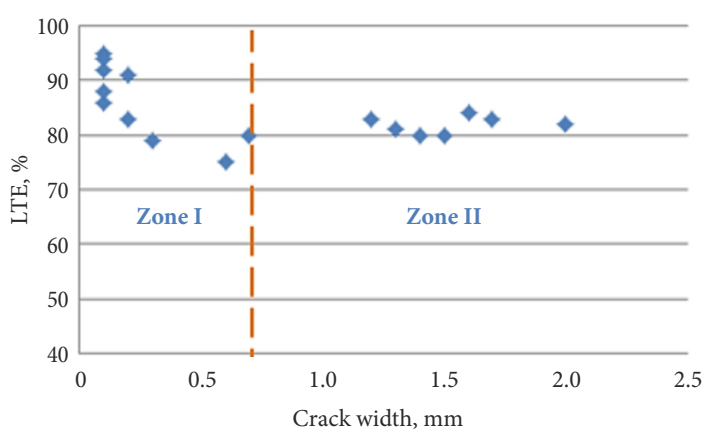

Figure 4. Results of LTE-crack width obtained in the field measurements

a) Function LTE-crack width of Zone I

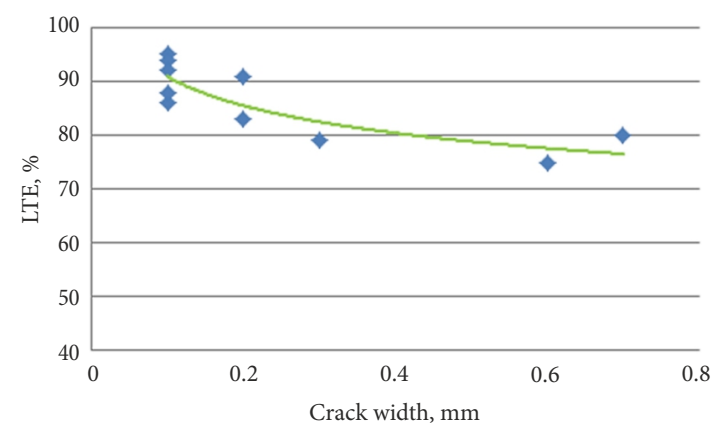

b) Zone II with extrapolation of function LTE-crack width of Zone I

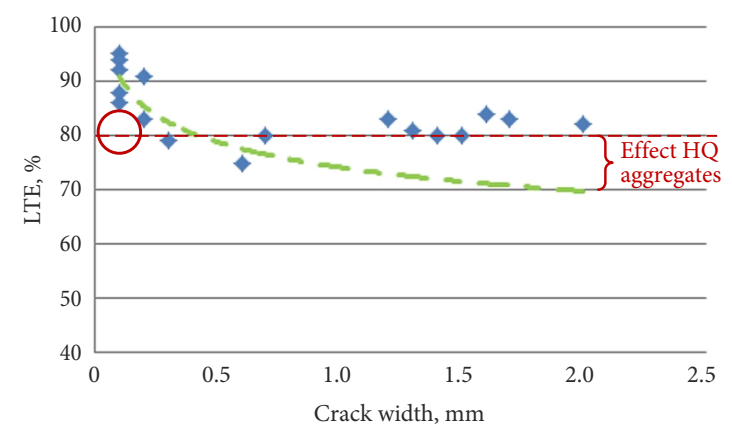

Figure 5. Effect of the high-quality aggregates on the LTE 
obtained with the Los Angeles method. For the aggregates of the Metropolitan Region (where the test section of NHL is located), the extremes of the Los Angeles abrasion values were $12 \%$ for the hardest aggregate, and $15 \%$ for the softest aggregate (Achurra, 2009). As a reference, the Los Angeles values of the South African aggregates were 21\% (for the hardest aggregates) and 33\% (for the softest one).

\subsection{Complementary field measurements with the Faultimeter}

The BRRC developed a Faultimeter that records the maximum relative movements of the slabs, while the rear axle of a truck passes from the approach slab to the leave slab. Although the Faultimeter does not measure the LTE, the BRRC has performed numerous measurements to compare the load transfer efficiency with the relative movements given by the Faultimeter. These field measurements have been performed with the Faultimeter and the FWD at many different JPCPs in Belgium (Perez et al., 2009; Perez \& Van Geem, 2010). In addition, the Faultimeter is able to record the Residual Value (RV) that indicates if the joint is interlocked, after the slabs have been relieved of the load (Perez et al., 2009; Perez \& Van Geem, 2010). In effect, Perez et al. (2009) and Perez and Van Geem (2010) clearly distinguishes the following two cases:

- when $\mathrm{RV}=0$ the joints are not interlocked;

- when RV $>0$ the joints are interlocked.

The determination of the existence of aggregate interlocking in the joints is very important and useful information for the purposes of the present research.

Figure 6 actually represents measurements performed with the Faultimeter in the Octave Region of Bio Bio (latitude $36^{\circ} 58^{\prime} \mathrm{S}$ ), Chile. These measurements were performed according to the specifications of the BRRC (Perez et al., 2009; Perez \& Van Geem, 2010) and in both traffic directions. The characteristics of the test section are as follows: slab length $4.0 \mathrm{~m}$, slab thickness $260.0 \mathrm{~mm}$, aggregates of $38.0 \mathrm{~mm}$ (maximum size), no dowel bars, granular base CBR 50\% and concrete flexural tensile strength 4.8 MPa. In particular, 8 joints with crack widths between
$0.1 \mathrm{~mm}$ and $1.2 \mathrm{~mm}$ were auscultated with the Faultimeter. Actually, although the 8 joints are part of a traditional JPCP, the magnitude of the (narrow) crack widths are explained by the high slab temperature at the time of the measurements (average $25^{\circ} \mathrm{C}$ at the slab surface measured with an infrared thermometer).

Although the very low relative movements $(<0.4 \mathrm{~mm})$ measured with the Faultimeter show the stability of the slabs, they are inconclusive in terms of a relationship with the LTE. However, in the 8 joints where the measurements have performed the result was RV $>0$, which indicate the interlocking of the joints. This RV result is an additional confirmation of the results of the previous sections regarding the provision of the aggregate interlock of crack widths between $0.1 \mathrm{~mm}$ and $1.2 \mathrm{~mm}$ (Figures 2, 4 and 5). Although the large slab thickness $(260 \mathrm{~mm})$ plays a role in the low vertical displacement of the slabs, the RV was given by the Faultimeter clearly shows the aggregate interlock in the joints.

\section{Conclusions}

1. The present article has been focused on the direct cause of the load transfer by aggregate interlock (i.e. the crack width) instead of indirect ones. In this way, it is possible to incorporate in Mechanistic-Empirical design methods for non-dowelled Jointed Plain Concrete Pavements the direct cause of the load transfer by aggregate interlock. This is especially important for the non-dowelled short concrete slabs where the load transfer relies on the aggregate interlock.

2. Due to the small crack widths, the non-dowelled short slabs pavements are able to provide adequate load transfer efficiency $(\geq 70 \%)$ even without dowels bars. Indeed, in this case, the load transfer relies on aggregate interlock and the results of the Faultimeter (residual value $>0$ ) have confirmed this interlocking for crack widths $\leq 1.2 \mathrm{~mm}$, which are the typical crack width values of concrete short slabs. a) Faultimeter position on a joint

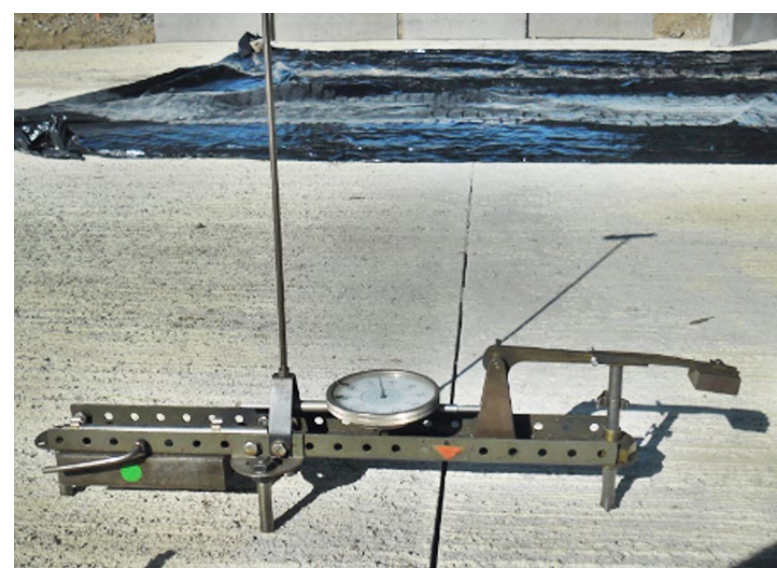

b) Reading the gauge of the Faultimeter

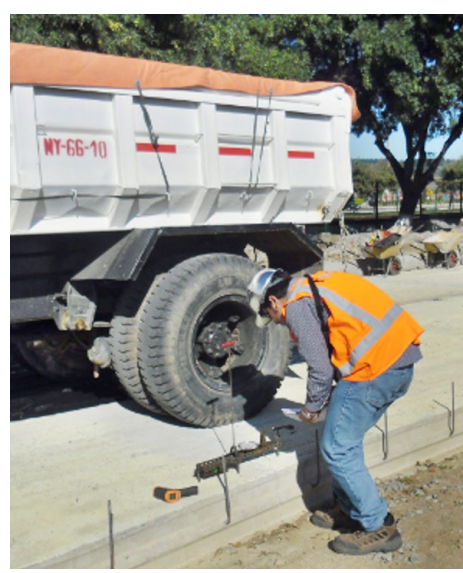

Figure 6. Measurements perfomed with the Faultimeter 
3. Especially, in short concrete slab pavements the joint activation is crucial with respect to the design hypothesis and to obtain the mentioned small crack widths. In this way, it is recommended to apply the Early Entry saw cutting method with modifications or as a complementary method to perform the joints of the pavement.

4. Although, in short concrete slab pavements the adequate provision of load transfer is already guaranteed by the small crack widths $(\leq 1.2 \mathrm{~m})$; the application of high-quality coarse aggregates provides even higher values of load transfer.

5. It is highly recommended to develop the relation load transfer-crack width (at joints) directly from field measurements or laboratory tests. Otherwise, the following possibilities are proposed:

- when high-quality aggregates are applied, the presented results of South Africa and Chile are useful as a reference;

- if no high-quality aggregates are applied, the 3D Finite Element program EverFE (with the validated nonlinear aggregate interlock model included) is used to generate specific curves loads transfercrack width or a set of characteristic curves. A more conservative approach is the direct application of the curve of validation of the nonlinear aggregate interlock model of EverFE.

\section{References}

Achurra, S. (2009). Procedure to measure and control of the superficial friction in Chilean pavements (in Spanish): MSc Thesis. Catholic University of Chile, Santiago, Chile.

Brink, A., Horak, E., Perrie, B., Strauss, P., \& Visser, A. (2004). Improvement of aggregate interlock equation used in cncPave. Proceedings of the 23rd Southern African Transport Conference. Pretoria, South Africa.

Buch, N., Frabizzio, M. A., \& Hiller, J. E. (2000). Impact of coarse aggregates on transverse crack performance in jointed concrete pavements. ACI Materials Journal, 97(3), 325-332.

Colley, B. E., \& Humphrey, H. M. (1967). Aggregate interlock at joints in concrete pavements. Bulletin HRB National Research Council, 189, 1-18.

Covarrubias, J. P. (2011). Design of concrete slabs with optimized geometry. Proceedings of 2nd International Conference on Best Practices for Concrete Pavements. Florianopolis, Brazil.

Covarrubias, J. P. (2012). Design of concrete pavement with optimized slab geometry. Revista Ingeniería de Construcción 27(3), 181-197.

Davids, W. G., \& Mahoney, J. P. (1999). Experimental verification of rigid pavement joint load transfer modeling with EverFE. Transportation Research Record, 1684, 81-89. https://doi.org/10.3141/1684-10

Hanekom, A. C., Horak, E.; Visser, A. T. (2001). Aggregate interlock load transfer efficiency at joints in concrete pavements during dynamic loading. Proceedings of the 7th International Conference on Concrete Pavements. Orlando FL, USA.

Hanekom, A. C., Horak, E.; Visser, A. T. (2003). Comparison of South African and American aggregate interlock efficiency at concrete pavement joints. Proceedings of the 16th ASCE Engineering Mechanics Conference. Seattle, USA.
Houben, L. J. M. (2010). Transversal cracking in jointed plain concrete pavements for Dutch climatic conditions. Proceedings of the 7th International DUT-Workshop on Design and Performance of Sustainable and Durable Concrete Pavement. Carmona, Spain.

Ioannides, A. M. (1984). Analysis of slabs-on-grade for a variety of loading and support conditions: $\mathrm{PhD}$ Thesis. University of Illinois, Urbana-Champaign, USA.

Ioannides, A. M., \& Korovesis, G. (1990). Aggregate interlock: a pure-shear load transfer mechanism. Transportation Research Record, 1286, 14-24.

Jensen, E., \& Hansen, W. (2001). Mechanism of load transfercrack width relation in JPCP: influence of coarse aggregate properties. Proceedings of the 7th International Conference on Concrete Pavements. Orlando, USA.

Perez, S., \& Van Geem, C. (2010). Evaluation by FWD and faultimeter of concrete slabs stability. 6th European FWD User Group Meeting Structural Condition Assessment. Sterrebeek, Belgium.

Perez, S., Beeldens, A., Maeck, J., Van Geem, C., Vanelstraete, A., Degrande, G., Lombaert, G., \& De Winne, P. (2009). Evaluation of the use of FWD and Faultimeter in the stabilizations of concrete slabs (in French). Proceedings of the 21st Belgian Congress of Roads. Gent, Belgium.

Pradena, M., \& Houben, L. J. M. (2014). Sustainable pavements: influence of the saw-cutting method on the performance of JPCPs. Proceedings of the 14th International Multidisciplinary Scientific GeoConference on Nano, Bio and Green Technology for a Sustainable Future. Albena, Bulgaria.

https://doi.org/10.5593/SGEM2014/B62/S26.043

Pradena, M., \& Houben, L. J. M. (2015). Analysis of the stress relaxation in plain concrete pavements. Baltic Journal of Road and Bridge Engineering, 10(1), 46-53. https://doi.org/10.3846/bjrbe.2015.06

Pradena, M., \& Houben, L. J. M. (2016). Sustainable pavements: correction factor for the modelling of crack width at joints of short slabs. Proceedings of the 16th International Multidisciplinary Scientific GeoConference on Nano, Bio and Green Technology for a Sustainable Future. Albena, Bulgaria.

Pradena, M., \& Houben, L. J. M. (2017). Influence of early-age concrete behaviour on concrete pavements performance. Journal Civil Engineer (Građevinar), 69(9), 875-883.

Roesler, J. R., Cervantes, V. G., \& Amirkhanian, A. N. (2012). Accelerated performance testing of concrete pavement with short slabs. International Journal of Pavement Engineering, 13(6), 494-507. https://doi.org/10.1080/10298436.2011.575134

Ruiz, J. M., Rasmussen, R. O., Chang, G. K., Dick, J. C., \& Nelson, P. K. (2005). Computer-based guidelines for concrete pavements, volume II: design and construction guidelines and HIPERPAV II user's manual. Report FHWA-HRT-04-122, Federal Highway Administration. McLean, VA.

Salsilli, R., Wahr, C., Delgadillo, R., Huerta, J., \& Sepúlveda, P. (2013). Design method for concrete pavements with short slabs based on Westergaard's equations and Dimensional analysis. Proceedings of the 92nd Transportation Research Board Annual Meeting. Washington DC, USA.

Salsilli, R., Wahr, C., Delgadillo, R., Huerta, J., \& Sepúlveda, P. (2015). Field performance of concrete pavements with short slabs and design procedure calibrated for Chilean conditions. International Journal of Pavement Engineering, 16(4), 363-379. https://doi.org/10.1080/10298436.2014.943129

Walraven, J. C. (1994). Rough cracks subjected to earthquake loading. Journal of Structural Engineering, 120(5), 1510-1524. https://doi.org/10.1061/(ASCE)0733-9445(1994)120:5(1510) 